\title{
Crustal structure beneath Beijing and its surrounding regions derived from gravity data*
}

\author{
Wenliang Jiang ${ }^{1, \star}$ Jingfa Zhang ${ }^{1} \quad$ Xiaocui $\mathrm{Lu}^{2}$ and Jing $\mathrm{Lu}^{1}$ \\ ${ }^{1}$ Institute of Crustal Dynamics, China Earthquake Administration, Beijing 100085, China \\ ${ }^{2}$ Science and Technology University of Shandong, Qingdao 252600, China
}

\begin{abstract}
In this paper we use gravity data to study fine crustal structure and seismogenic environment beneath Beijing and its surrounding regions. Multi-scale wavelet analysis method is applied to separating gravity fields. Logarithmic power spectrum method is also used to calculate depth of gravity field source. The results show that the crustal structure is very complicated beneath Beijing and its surrounding areas. The crustal density exhibits laterally inhomogeneous. There are three large scale tectonic zones in North China, i.e., WNW-striking Zhangjiakou-Bohai tectonic zone (ZBTZ), NE-striking Taihang piedmont tectonic zone (TPTZ) and Cangxian tectonic zone (CTZ). ZBTZ and TPTZ intersect with each other beneath Beijing area and both of them cut through the lithosphere. The upper and middle crusts consist of many small-scale faults, uplifts and depressions. In the lower crust, these small-scale tectonic units disappear gradually, and they are replaced by large-scale tectonic units. In surrounding regions of Beijing, ZBTZ intersects with several other NE-striking tectonic units, such as Cangxian uplift, Jizhong depression and Shanxi Graben System (SGS). In west of Taihangshan uplift, gravity anomalies in upper and middle crusts are correlated with geological and topographic features on the surface. Compared with the crust, the structure is comparatively simple in uppermost mantle. Earthquakes mainly occurred in upper and middle crusts, especially in transitional regions between high gravity anomaly and low gravity anomaly. Occurrence of large earthquakes may be related to the upwelling of upper mantle and asthenosphere heat flow materials, such as Sanhe earthquake $\left(M_{\mathrm{S}} 8.0\right)$ and Tangshan earthquake $\left(M_{\mathrm{S}} 7.8\right)$.
\end{abstract}

Key words: Beijing area; fine structure; crust and upper mantle; Bouguer gravity anomaly; wavelet multi-scale analysis

CLC number: P315.2 Document code: A

\section{Introduction}

The North China Craton is an old tectonic unit in Chinese mainland. It is also one of the most active intracontinental regions in the world. Beijing is situated in northwestern part of North China basin (NCB). The western and northern portions of NCB are Taihangshan uplift and relatively stable Yanshan uplift, respectively. There are many active faults with different strikes (Figure 1), which makes Beijing one of the most complicated tectonic areas in eastern China. The Cenozoic

\footnotetext{
* Received 7 September 2010; accepted in revised form 5 January 2011; published 10 June 2011.

+ Corresponding author. e-mail: jiang_wenliang@163.com

(C) The Seismological Society of China and Springer-Verlag Berlin Heidelberg 2011
}

era Zhangjiakou-Bohai tectonic zone (ZBTZ) is the most important tectonic system in NCB (Ye et al., 1985; Liu, 1987), to which the occurrences of most large earthquakes in NCB are related (Xu et al., 1998; Wang et al., $2004)$, such as Sanhe earthquake $\left(M_{\mathrm{S}} 8.0\right)$ and Tangshan earthquake $\left(M_{\mathrm{S}} 7.8\right)$. Besides, more than 20 earthquakes with magnitude larger than M6.0 occurred in ZBTZ in history. Therefore, it is necessary to study the fine crustal structure and seismogenic environment of Beijing and its adjacent regions.

In the last three decades, many researchers have investigated seismic structure of the North China using seismic tomography method (Jin et al., 1980; Liu et al., 1989; Sun and Liu, 1995; Yu et al., 2003; Huang and Zhao, 2004, 2009; Wang et al., 2005; Li et al., 2006; Qi et al., 2006; Wu et al., 2007; Lei et al., 2008; Fang et 


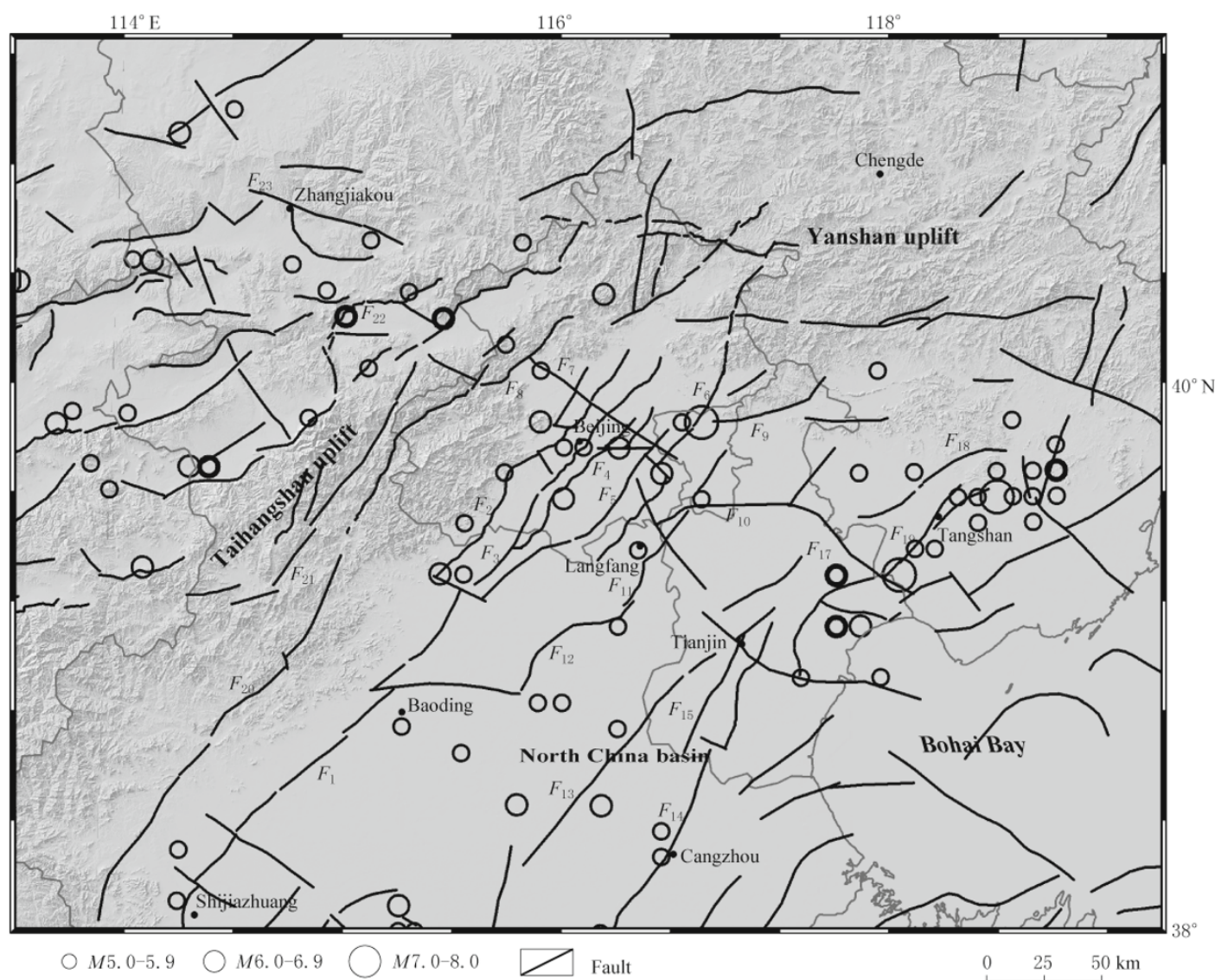

Figure 1 Topographic map of the study area showing the major active faults. Grey curves show the boundaries between provinces. Black curves show major active faults. $F_{1}$. Baoding-Shijiazhuang fault; $F_{2}$. Huangzhuang-Gaoliying fault; $F_{3}$. Shunyi-Liangxiang fault; $F_{4}$. Nanyuan-Tongxian fault; $F_{5}$. Daxing fault; $F_{6}$. Xiadian fault; $F_{7}$. Nankou-Sunhe fault; $F_{8}$. Nankou piedmont fault; $F_{9}$. Jixian fault; $F_{10}$. Baodi fault; $F_{11}$. Hexiwu fault; $F_{12}$. Southern Niutuozhen fault; $F_{13}$. Southern Tianjin fault; $F_{14}$. Cangdong fault; $F_{15}$. Northern Tianjin fault; $F_{16}$. Haihe fault; $F_{17}$. Jiyunhe fault; $F_{18}$. Zhenzizhen fault; $F_{19}$. Tangshan fault; $F_{20}$. Zijinguan fault; $F_{21}$. Sunzhuangzi-Wulonggou fault; $F_{22}$. Northern Yanfan basin fault; $F_{23}$. Zhangjiakou fault.

al., 2009), and obtained many results about seismic wave velocity structure. Huang and Zhao (2004, 2009) and Lei et al. (2008) also studied seismogenic process in NCB. Their results reported that large crustal earthquakes, such as 1695 Sanhe earthquake, 1976 Tangshan earthquake and the 2006 Wenan earthquake, generally occurred in high-velocity areas from the upper to middle crust, and were mainly induced by weakening of the seismogenic layer caused by fluids in the lower crust (Huang and Zhao, 2004; Lei et al., 2008). The earthquakes are induced by upwelling of the hot and wet asthenospheric materials due to the deep dehydration of the stagnant Pacific slab in the mantle transition zone (Lei et al., 2008; Huang and Zhao, 2009). However, due to sparse distribution of seismic stations, the resolution and reliability of the previous velocity models were reduced. And weak anomalies caused by small-scale tec- tonic units cannot be revealed by previous seismic wave velocity structures. So other effective methods are needed to study fine crustal structure beneath Beijing and its surrounding regions.

As well known, it has been a long time since gravity method was used to study crustal structure. Nowadays the method still plays an important role in the research on Earth's interior structure. Rocks with different densities can be distinguished using Bouguer gravity data, and density interfaces can also be inverted. Thus the tectonic units with different rock densities and density interfaces can be determined. Bouguer gravity data contain gravitational information related to the whole lithosphere, which can not only reflect vertical layer variation of the lithosphere, but also reveal laterally heterogeneity of lithospheric density. In order to study different layers, we must adopt proper methods to separate gravity 
field in multi-scale. This is the key step to invert and interpret geologic bodies (Zeng, 2005; Diao et al., 2007).

Now lots of work has been done on crustal structure in North China using gravity method (Feng et al., 1989; Fang et al., 2002; Zhang and Wang, 2005; Jiang et al., 2010). Fang et al. (2002) used multi-scale decomposition technique of wavelet transform to study crustal structure in North China, revealed gravity anomalies originated from anomalous density bodies of various scales from surface to Moho, and then discussed the deep structure setting for the strong earthquakes in this region. However, it is not enough to study more deeply seismogenic environment in Beijing and its neighboring areas. Therefore, it is meaningful for us to study fine crustal structure and seismogenic environments using advanced potential field separation method and largescale gravity data in these areas.

\section{Data and methods}

In this study we apply wavelet multi-scale analysis method to separating Bouguer gravity field. Surface gravity data with sample interval of $2 \mathrm{~km}$ were collected. The data is issued by Development and Research Center, China Geological Survey in 2002. Seismic tomography results are referred to compare with gravity inversion results.

Gravity field affects the whole lithosphere. Conventional methods for gravity field separation include analytic extension, trend analysis and derivative method, etc. But these methods all depend on separation of regional and local fields, so they are not suitable for separating multi-scale gravity anomalies. The wavelet multi-scale analysis method has been developed greatly in recent years, and widely used in geophysical data processing, especially in gravity anomaly processing (Hou and Yang, 1997; Zhang and Qiu, 1998; Yang et al., 2001; Chen, 2004; Liu et al., 2004; Lou and Wang, 2005; Wang, 2005; Zhang et al., 2006; Diao et al., 2007; Pei et al., 2007; Wang et al., 2009). Hou and Yang (1997) firstly used wavelet transform and multi-scale analysis method to study gravity anomalies of China. Yang et al. (2001) applied wavelet analysis method to gravity anomaly separation and processing, and introduced a new method to gravity anomalies separation. Chen (2004), Wang (2005) and Wang et al. (2009) have also done lots of simulated experiments with wavelet analysis method, which proved the method effective in the 3D inversion on gravimagnetic field of arbitrary geological bodies.
The main idea of multi-scale analysis is to decompose spatial domain $L^{2}(R)$ into a series of sub-spaces with different resolutions, of which the limit is $L^{2}(R)$; and then describe functions in $L^{2}(R)$ as approximate limits of the series of approximate functions. Each of approximate function is projection of original function on sub-spaces with different resolutions. The most common algorithm applied to wavelet multi-scale analysis is pyramid decomposition and reconstruction algorith$\mathrm{m}$. On the base of wavelet multi-scale analysis, Mallat (1989) integrated construction method of orthonormal wavelet base according to characteristics of wavelet multi-resolution, and proposed the construction method and fast transform algorithm of orthonormal wavelet, which is also called Mallat Algorithm. Theory and flow of Mallat Algorithm can refer to related literatures (Mallat, 1989; Mallat and Hwang, 1992; Hou and Yang, 1997; Yang et al, 2001).

Approximation image of wavelet reflects the regional gravity field, which contains low-frequency gravity anomalies produced by deep large-scale geologic bodies. While detailed image of wavelet reflects the local gravity field, which contains high-frequency gravity anomalies caused by shallow small-scale geological bodies. As we known, the larger is the wavelet multi-scale transform order, the deeper the source depth will be. However, the exact depth information cannot be obtained directly. Logarithm power spectrum is another method to process gravity and magnetism data in the last century (Cianciare and Marcar, 1976). On the assumption of that source field depth is correlated with power spectrum, we can obtain average depth information based on slope of logarithm power spectrum curve. Thus, we can get depth information of field source displayed by approximate images and detailed images.

Seismic tomography is a method to invert physical properties using seismic data, which can display lateral image of the lithosphere. Its purpose is to study 3D seismic wave velocity structure of the crust to determine the fine structure of the Earth's interior and local inhomogeneity (Yang, 1993). Density is one of the most important factors which affect P- and S-wave velocities. Gardner et al. (1974) firstly studied relation between average seismic wave velocity and rock density. Other empirical formulae were also obtained successively according to different rock experiments (Castagna et al., 1985; Han et al., 1986, 1997; Smith and Gidlow, 1987; Li, 1992; Mavko et al., 1998; Ma and Xie, 2005). All results indicated that seismic $\mathrm{P}$ - and S-wave velocities are related to lithospheric density, and with the densi- 
ty increasing, the velocity increases to a certain extent. Based on the influence of lithospheric density on gravity field and seismic wave velocity, we can analyze relation between gravity anomaly and wave velocity anomaly qualitatively and further to study fine crustal structure beneath Beijing and its surrounding regions.

\section{Inversion and analysis}

We separate the Bouguer gravity field into subspace and reseparate each subspace into new order subspace until no local field anomaly can be found in approximate image. Such approximate image only contains Bouguer gravity anomalies produced by upper mantle, while the detailed image with the same order can reflect Bouguer gravity anomalies produced by lower crust and uppermost mantle. Six orders of wavelet multi-scale analyses are performed based on Bouguer gravity data. We compute approximate source depths of detailed images using logarithm power spectrum method as listed in Table 1. Because the average thickness of the crust in Beijing area is about $34 \mathrm{~km}$ (Luo et al., 2008), the first- to second-order, third-order, fourth-order and fifth-order images can reveal the structures of upper crust, middle crust, lower crust and uppermost mantle, respectively.

According to the inversion results, lithospheric density is obviously laterally inhomogeneous beneath Beijing area. And Bouguer gravity anomalies are more complicated in upper and middle crusts than those in lower crust and deeper positions. Detailed crustal structure in Beijing and its adjacent areas will be described later.

Table 1 Approximate source depths of 1st- to 5th-order detailed images calculated from power spectrum method

\begin{tabular}{lc}
\hline Order & $\begin{array}{c}\text { Approximate field } \\
\text { source depth } / \mathrm{km}\end{array}$ \\
\hline First-order & 3 \\
Second-order & 6 \\
Third-order & 15 \\
Fourth-order & 27 \\
Fifth-order & 40 \\
\hline
\end{tabular}

\subsection{Regional tectonic characteristics}

Bouguer gravity anomalies produced by regional field sources are shown in Figure 2. The approximate source depths in Figures $2 \mathrm{a}$ and $2 \mathrm{~b}$ are located at mid- dle and lower crusts, respectively. Two large gravitational gradient zones can be found in the figure, striking NNE and nearly EW, respectively. The larger one names Taihangshan gravitational gradient zone extending along Taihangshan, and it is part of Daxing'anlingTaihangshan-Wuyishan Gravitational Gradient Zone, which is a famous gravitational gradient zone in Chinese mainland (Yin et al., 1980; Liu, 2002; Ma et al., 2006). It maybe result from NSward extrusion stress produced by collision of North China block and Huanan block in Late Indosinian (Ma et al., 2006), or maybe result from interaction of Indian plate, Eurasian plate and Pacific plate, deep mantle flow and heat mantle column (Yang et al., 2005). It divides North China into two parts. North China basin (NCB) in the east exhibits smooth gravity anomalies, whereas Taihangshan uplift in the west exhibits large-scale low gravity anomalies. Gravity values decrease from $2.0 \times 10^{-4} \mathrm{~m} \cdot \mathrm{s}^{-2}$ in NCB to $1.2 \times 10^{-3}$ $\mathrm{m} \cdot \mathrm{s}^{-2}$ in Shanxi areas, with the maximum gradient larger than $1.0 \times 10^{-5} \mathrm{~m} \cdot \mathrm{s}^{-2} \cdot \mathrm{km}^{-1}$. This reflects crust thickness in the east is smaller than that in the west, according to the negative correlation between gravity and topography. Earlier studies have already proved the fact (Li et al., 1984; Ma and Zheng, 1998; Luo et al., 2008). The EW-striking Yanshan sub-gravitational gradient zone constitutes boundary of southern North China basin and northern Yanshan fold belt. And the gravity change from $1.0 \times 10^{-4} \mathrm{~m} \cdot \mathrm{s}^{-2}$ to $4.0 \times 10^{-3} \mathrm{~m} \cdot \mathrm{s}^{-2}$ across the Yanshan uplift. So we conclude that Taihangshan gravitational gradient zone and Yanshan subgravitational gradient zone form two important geological and geophysical boundaries in North China.

Figure 2 shows high gravity anomalies in Cangxian uplift and Tangshan area, especially in Tangshan area, with largest Bouguer gravity anomaly up to about $3 \times 10^{-4} \mathrm{~m} \cdot \mathrm{s}^{-2}$. This reflects the Moho discontinuities in the two places are shallower than that in their surrounding areas. We will then analyze the fine structural characteristics of lithosphere from bottom to top hierarchical based on detailed images.

\subsection{Uppermost mantle structure}

Approximate source depth of the fifth-order detailed image (Figure 3e) is under the lower crust. The above two tectonic zones still show high gravity anomalies. Besides, the NCB is interlaced with several low and high gravity anomalies, and they all intersect with ZBTZ. From west to east, the corresponding geological bodies are Jizhong depression, Cangxian uplift and 

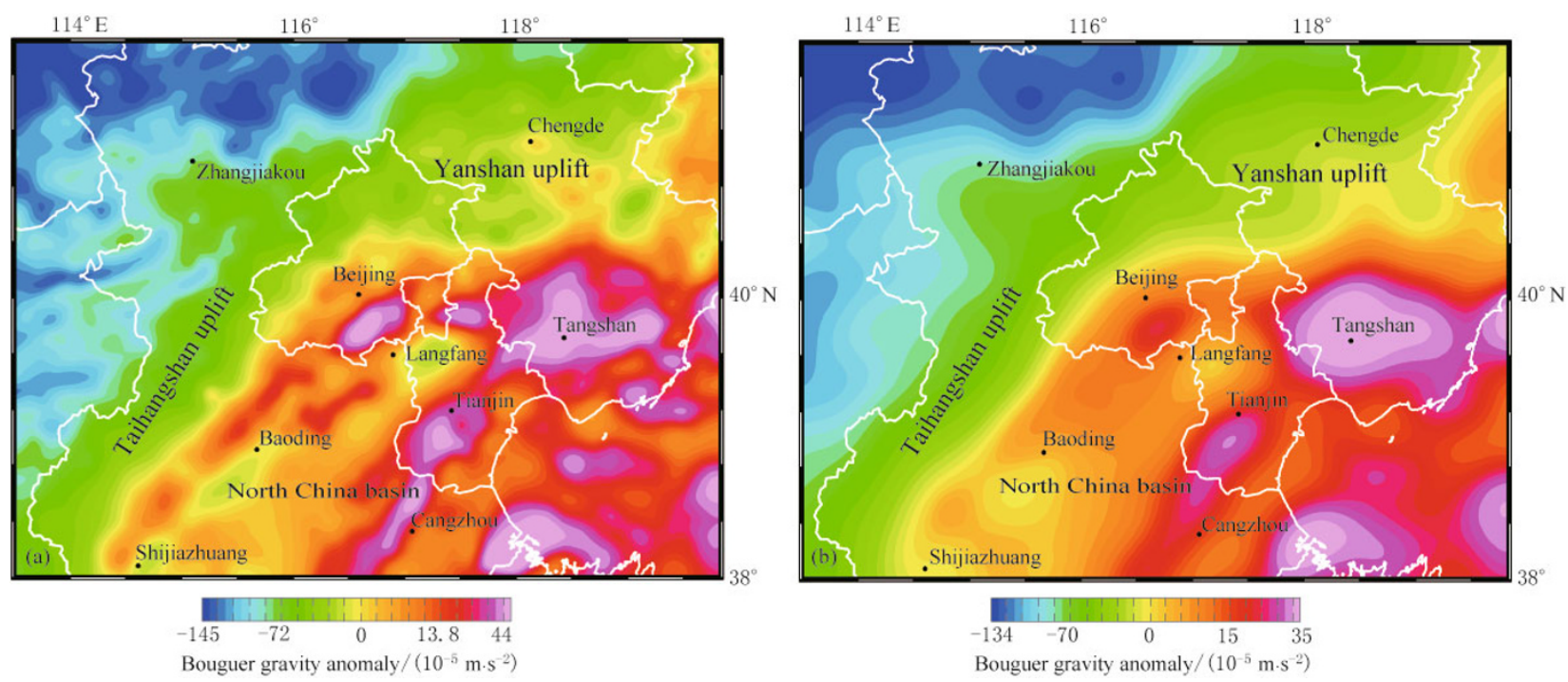

Figure 2 Wevelet multi-scale analysis images of Bouguer gravity anomalies. (a) and (b) correspond to the 2nd and 4th order wavelet transform approximate images of the Bouguer gravity anomalies, respectively.

Huanghua depression. Larger gravitational gradient zones, produced by fault tectonic, exist between high and low anomalies. These tectonic units form the basic framework of NCB. Phenomenon of upwelling of upper mantle and asthenospheric heat flow materials along TPTZ and ZBTZ still exists according to the exhibitions of high gravity anomalies in fifth-order detailed image (Figure 3e). And the Taihangshan piedmont high gravity anomaly is about $70 \mathrm{~km}$ long and $40 \mathrm{~km}$ wide. In ZBTZ, Beijing and Tangshan areas are high gravity anomalies. Figure 2 also shows high gravity anomaly in Daxing uplift. As the largest tectonic unit beneath Beijing, the Daxing uplift is located in interaction area of ZBTZ and TPTZ, so we can infer the anomaly was caused by the upwelling of upper mantle and asthenospheric material with high density. Jizhong depression is the largest tectonic unit in $\mathrm{NCB}$, and exhibits low gravity anomaly in Figure 3e. It is surrounded by north Yanshan uplift, west Taihangshan uplift and east Cangxian uplift and is a Cenozoic sedimentary depression growing on old platform substrate in North China. Besides, Jizhong depression is composed of many smallscale uplifts and depressions, among which Wuqing depression shows the most clear anomaly in detailed image. Northwest of Wuqing depression is Daxing uplift, and north is Jixian uplift. In Figure 3e, Cangxian uplift exhibits high anomaly with about $50 \mathrm{~km}$ in wide and strike in NE. A blind fault named Jinghai-Xianxian fault constitutes the boundary of Cangxian uplift and Jizhong depression, and it is a famous Cenozoic seismic belt in eastern China (Xu et al., 1996). In the intersect area of ZBTZ and Cangxian uplift, the gravity anomaly is very high, and earthquakes occur frequently there. Tangshan earthquake $\left(M_{\mathrm{S}} 7.8\right)$ is inferred to be correlated with the upwelling of upper mantle and heat flow materials of asthenosphere.

In northwest of the study area, ZBTZ intersect$\mathrm{s}$ with Shanxi graben system (SGS). Except Xuanhua basin, large-scale low gravity anomalies exist beneath Taihangshan area. The low gravity anomaly of Yanqing basin divides ZBTZ into two parts. Xuanhua basin shows high gravity anomaly, which may be due to upper mantle uplift. So thickness of crust beneath Xuanhua basin is smaller than that in surrounding areas. Although Southeast of Xuanhua basin shows high gravity anomaly, there are several low gravity anomaly circles produced by small Cenozoic era graben basins. These basins are not only important sections of ZBTZ, but also parts of NNE-striking SGS.

From the above analyses we know Bouguer gravity anomalies are obvious, and they reflect basic tectonic framework of uppermost mantle beneath Beijing and its surrounding regions. High density materials of uppermost mantle and asthenosphere upwell greatly along ZBTZ and TPTZ. They are mostly induced by subduction of Pacific plate beneath Eurasian plate.

\subsection{Lower crustal structure}

The source depth of fourth-order detailed image (Figure 3d) is shallower than that of fifth-order detailed image. According to the calculation using logarithm 

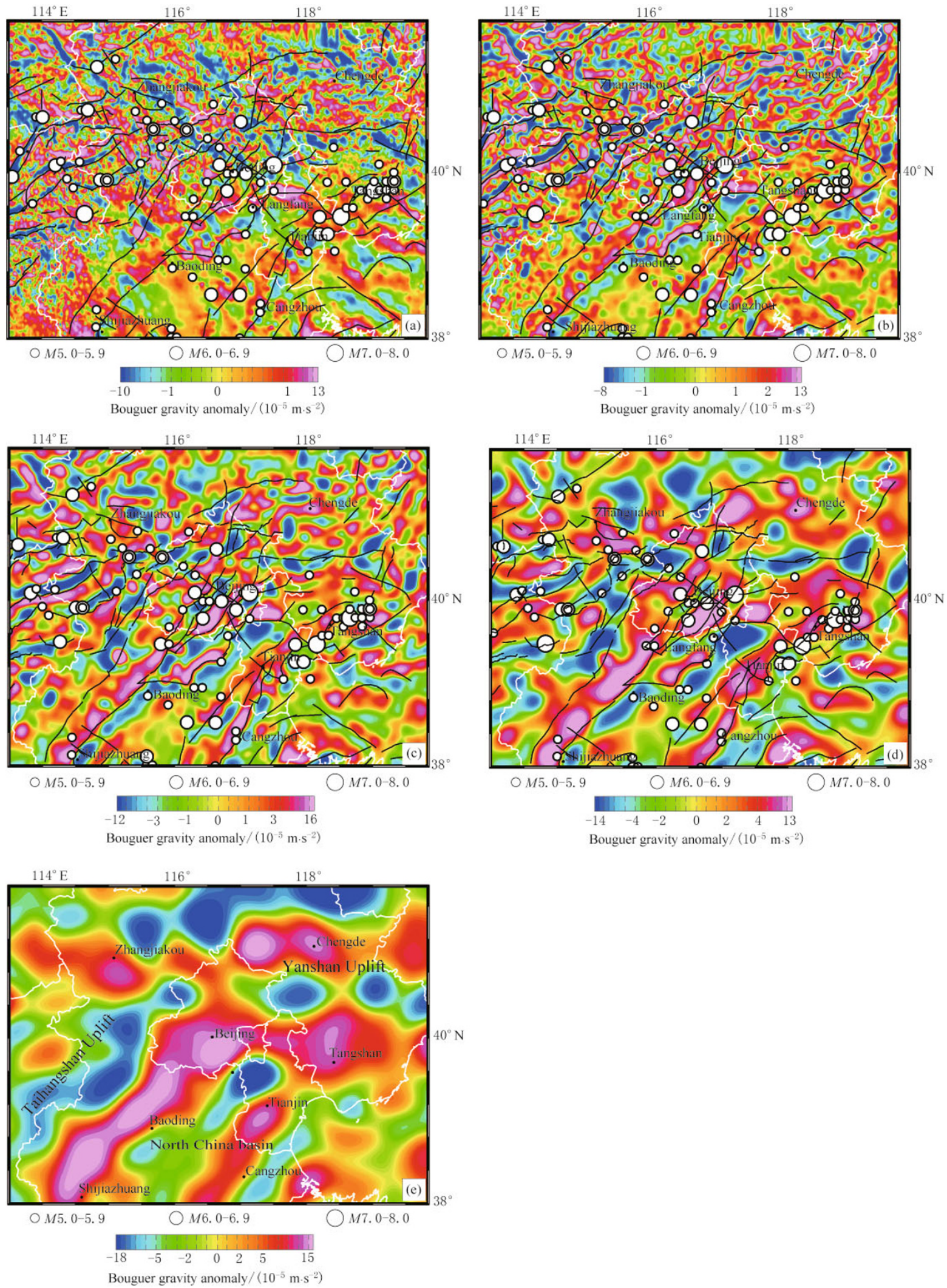

Figure 3 Wevelet multi-scale analysis images of Bouguer gravity anomalies. (a) to (e) correspond to the 1st to 5 th order wavelet transform detailed images of the Bouguer gravity anomalies, respectively. 
power spectrum method, fourth-order detailed image is about $27 \mathrm{~km}$ in depth. So, it reflects the lower crustal structure. There are many high and low gravity anomalies in ZBTZ as shown in Figure 3d. The large secondary tectonic units in NCB are decomposed into many smallscale units, making lower crustal structure beneath Beijing and its surrounding areas very complicated. So the Bouguer gravity anomalies become complicated and crustal density becomes lateral inhomogeneous in lower crust.

In south of Zhuozhou area, there exist two parallel gravity anomaly zones along the Taihangshan piedmont areas, the left one is of high anomaly and the right one is of low anomaly; the gravitational gradient zone between them reveals the existence of ShijiazhuangBaoding fault. As the west boundary of Jizhong depression, the Shijiazhuang-Baoding fault controls deposition boundary of NCB. In north of Zhuozhou, gravity anomaly becomes complex as shown in the fourth-order detailed image (Figure 3d). Several high and low anomalies interlace beneath Beijing, with the strikes similar to Shijiazhuang-Baoding fault. So it is inferred that they belong to the same tectonic system, named TPTZ. Influenced by both ZBTZ and TPTZ, crustal structure is very complicated beneath Beijing. Many small-scale tectonic units grow there, including Huangzhuang-Gaoliying fault, Liangxiang-Shunyi fault, Nanyuan-Tongxian fault, Xiadian fault and eastern margin fault of Daxing uplift. They divide the crust into many different sections, and formed the fastigiate distributed feature in front of Taihangshan piedmont area. There occurred frequently small earthquakes, and the largest one is Sanhe earthquake $\left(M_{\mathrm{S}} 8.0\right)$, which just happened on Xiadian fault. It is inferred that the mechanism of Sanhe earthquake is similar to that of Tangshan earthquake. They are both induced by the upwelling of upper mantle and asthenosphere heat flow materials.

And the highest Bouguer gravity value of Cangxian uplift is about $7 \times 10^{-5} \mathrm{~m} \cdot \mathrm{s}^{-2}$, which is much smaller than Bouguer gravity value in Taihangshan piedmont, indicating the upwelling of upper mantle beneath Cangxian uplift is weaker than that along TPTZ. There exhibit low anomalies on both sides of Cangxian uplift, which are caused by Jizhong and Huanghua depressions. From Figure 3d, we can see Jizhong depression becomes complicated in structure. And it consists many small scale tectonic units, including Niutuozhen, Gaoyang, Ningjin uplifts, and Gu'an, Hejian, Baxian, Renqiu, Baoding, Shijiazhuang depressions (Zhang et al., 2004; Zhang et al., 2008). The obviously low Bouguer gravity anomaly appears in Wuqing depression, with the smallest Bouguer gravity value about $1.6 \times 10^{-4} \mathrm{~m} \cdot \mathrm{s}^{-2}$. Density of Jizhong depression is laterally inhomogeneous.

\subsection{Middle crustal structure}

Middle crustal structure will be analyzed based on the third-order detailed image of wavelet multi-scale analysis (Figure 3c). The approximate source depth is about $15 \mathrm{~km}$. Bouguer gravity anomalies on both third and fourth order detailed images have the similar characteristics in figure, direction and correlation of gravity anomaly. However, density difference is more obvious in third-order detailed image. In this case crustal structure revealed by Bouguer gravity anomalies is more complicated in middle crust.

Beneath Beijing area, Bouguer gravity anomalies are more obvious in middle crust than in lower crust. Gravity gradient zones induced by small-scale fault tectonic units are linearly distributed. These reflect crustal structure is complicated in middle crust beneath Beijing area. In NCB, Bouguer gravity values are between $-2.0 \times 10^{-5} \mathrm{~m} \cdot \mathrm{s}^{-2}$ and $4.0 \times 10^{-5} \mathrm{~m} \cdot \mathrm{s}^{-2}$. The three largescale tectonic units, i.e., Jizhong depression, Cangxian uplift, Huanghua depression, are composed of many small-scale tectonic units, where different high and low Bouguer gravity anomalies appeared. These units are product of different processes of extrusion and extension movement experienced by North China. The subduction of Pacific plate to Eurasian plate contributes to these processes greatly. The crustal structure of Jizhong depression is very complex in third-order detailed image. The most clear gravity anomalies appear in Wuqing depression and Jixian uplift, which are located in the intersect area of Jizhong depression and ZBTZ. The Jixian uplift is on the edge of Yanshan uplift, where small earthquakes occurred frequently. The Baodi fault situated between Jixian uplift and Wuqing depression controls the deposition boundary of Jizhong depression.

Compared with the gravity anomalies of lower crust, anomaly of middle crust is more complicated in western Taihangshan area. The Taihangshan uplift is interlaced with many small-scale high and low anomalies, which are correlated with surface geological and topographic features. The crustal density becomes laterally inhomogeneous in middle crust. In third-order detailed image (Figure 3c), gravity anomalies distribute in narrow stripes, with low anomalies lying in the basin and high anomalies on both sides. Along the edges of basins, a series of boundary faults, including Yan- 
fan basin, Huaizhuo basin, Weiguang basin, Yangyuan basin and Huaianzhen basins, produce gravitational gradient zones, and cut down into the middle crust. All these tectonic units are productions of interaction between ZBTZ and Taihangshan uplift zone.

\subsection{Upper crustal structure}

The approximate source depth of second-order detail image is about $6 \mathrm{~km}$ (Figure 3b). As can be seen in Figures $3 \mathrm{~b}$ and $3 \mathrm{c}$, there are lots of similarities, which reflects crustal structures are similar in the two depths. However, gravity anomalies of second-order detailed image are more complex than third-order detailed image. Large secondary tectonic units still show obvious gravity anomalies, such as Jizhong depression, Cangxian uplift and Huanghua depression.

As for the small-scale tectonic units including Daxing uplift, Beijing depression and Sanhe depression, appear clear gravity anomalies, but they are smaller in size than those in the third-order detailed image. The faults among these tectonic units divide upper crust into many different sections. In seismic image of $\mathrm{P}$-wave velocity structure (Wang et al., 2005), east of HuangzhuangGaoliying fault is of low velocity anomaly, and meanwhile of low gravity anomaly. North of Xiadian fault is cut by high velocity body, with low velocity anomaly in the east, while in gravity anomaly image appears high gravity anomaly in north and low gravity anomaly in east. The crustal structure beneath Beijing inverted by gravity method is coincident with that from seismic tomography. From Figure 3b we can see that Baodi uplift shows high gravity anomaly with about $40 \mathrm{~km}$ long. In Tangshan area, the high gravity anomaly is very obvious and it is related to high anomaly produced by Cangxian uplift.

In northwest of Beijing, the Bouguer gravity anomalies are completely correlated with geological and topographic features in upper and middle crusts. According to seismic tomography results, northeast of Beijing, Yangyuan basin, Weixian basin and Huailai basin all show low velocity anomalies, and the piedmont fault zone of Taihangshan is intermitted by low velocity anomalies in depth of $10 \mathrm{~km}$ (Huang and Zhao, 2005). These reflect the upper crustal density of northwestern Beijing is smaller than that of its surrounding areas.

The first-order detailed image reveals source depth on top of the upper crust, i.e., about $3 \mathrm{~km}$ beneath the surface (Figure 3a). Because of the thick Cenozoic era sediments, Bouguer gravity changes smoothly in the NCB. Compared with the second-order detailed image, anomalies produced by small-scale tectonic units are not obvious. All these reflect density differences are not clear in lateral sediments. However, regional anomalies produced by the secondary tectonic units still exist, such as low gravity anomaly of Jizhong depression, high gravity anomaly of Cangxian uplift and low gravity anomaly of Huanghua depression. According to seismic tomography results, the NCB is interlaced with low and high $\mathrm{P}$-wave velocity anomalies in upper crust between $1 \mathrm{~km}$ and $5 \mathrm{~km}$ depth (Lei et al., 2008), such as low velocity anomaly of Jizhong depression, high velocity anomaly of Cangxian uplift and low velocity anomaly of Huanghua depression.

ZBTZ is intermitted with high anomalies. Jizhong uplift still shows high gravity anomaly, the upper interface of the uplift raises to the surface. Besides, gravity anomalies change sharply in northern Yanshan fold belt and western Taihangshan uplift. And anomalies are correlated with the surface geological and topographic features. Faults on edges of basins cut through the surface. The crustal structure is complex in mountainous regions.

\section{Discussion}

For earlier studies used low spatial resolution gravity data, or applied conventional methods, fine crustal structure could not be obtained beneath Beijing and its surrounding areas (Yin et al., 1993; Fang et al., 2002). Besides, active tectonics was not taken into consideration in some studies, therefore the relationships between gravity anomalies and earthquakes were not analyzed very well (Feng et al., 1989). In the present study, we applied advanced wavelet multi-scale analysis method to separating gravitational potential field based on largescale gravity data, and then studied fine crustal structure and seismogenic environment beneath Beijing and its surrounding regions.

Analyses of approximate images indicate there are two large scale gravitational gradient zones in the study areas, i.e., Taihangshan and Yanshan gravitational gradient zones. They are produced by Taihangshan uplift and Yanshan uplift, respectively. The North China is divided by TPTZ and ZBTZ into different parts. The two tectonic zones cut through the lithosphere. Bouguer gravity anomalies produced by the two tectonic zones exist in all approximate images. Tangshan is situated in the middle part of ZBTZ, and it exhibits large-scale high gravity anomalies. This suggests higher density materials exist beneath Tangshan area compared with its surrounding areas. The occurrence of Tangshan earthquake 
$\left(M_{\mathrm{S}} 7.8\right)$ is related to the upwelling of upper mantle and asthenospheric heat flow materials. Besides, Cangxian uplift exhibits high gravity anomalies, which is also produced by uplift of uppermost mantle.

Moreover, detailed images reflect that crustal structure is complicated beneath the NCB, especially in the upper and middle crusts. The crustal density is laterally inhomogeneous. The NCB is interlaced high and low gravity anomalies with NE-strike, which are produced by Jizhong depression, Cangxian uplift and Huanghua depression, etc. They are important secondary tectonic units in North China, and intersect with ZBTZ. In seismic images of wave velocity structure, they represent low and high velocity anomalies in upper crust. These secondary tectonic units are composed of many small-scale faults, uplifts and depressions, which makes the crust very complicated compared with the uppermost mantle. Many earthquakes occurred in the transitional areas between high and low gravity anomalies, which are produced by different uplifts and depressions. This is consistent with the previous researches, which considered strong earthquakes mostly happened near the gravitational gradient zone of high density geological bodies (Fang et al., 2002). Comparatively speaking, structure of the uppermost mantle is simple, and mainly composed of the above secondary tectonic units. It is worth emphasizing that Cenozoic era Cangxian uplift is an important seismic belt, and it intersects with ZBTZ in Tianjin and Tangshan areas. Throughout the whole crust, Cangxian uplift shows high gravity anomalies. And the famous seismic belt, Tangshan-Hejian seismic belt, extends along western side of Cangxian uplift. The complex sub-tectonic units in the North China riftdepression basin are characterized by sinking and fragmentized basement, uplifted Moho, thinned crust and lateral tectonic differences (Jia and Zhang, 2005; Jia et al., 2009).

Bouguer gravity anomalies in northwest of Beijing area are correlated with surface geological and topographic features in upper and middle crusts. In first and fourth order detailed images, anomalies distribute as narrow bands along basins. Low gravity anomalies exist in the basin, while on both sides of the basin appear high gravity anomalies. The gravitational gradient zones between the low and high gravity anomalies reveal the existence of faults, which cut through the surface. The phenomena are very clear in the first and second order detailed images. These basins include Yanhuai basin, Xuanhua basin and Yangyuan-Weixian basin, and they are located in intersecting area of ZBTZ and SGS. With the source depth increasing, the local gravity anomalies produced by these small basins disappear gradually, and are replaced by regional low gravity anomalies, indicating the lower crust is in state of mass deficit under the adjustment of gravity isostatic with the uplift of Taihangshan.

Influenced by interaction between Cenozoic era ZBTZ and TPTZ, the crustal structure beneath Beijing is very complicated. The crustal density is laterally inhomogeneous. Holocene sediments have covered the bumpy and fragmentized crust beneath Beijing, which consists many small-scale faults, uplifts and depressions, such as Daxing uplift, western uplift of Beijing, Beijing depression, Wuqing depression, Gu'an depression and the fault tectonics dividing them. Local gravity anomalies produced by these units are clearly displayed in the first to fourth order detailed images. Beneath the crust, the structure is simple in uppermost mantle, with the small fault tectonics disappearing, and the Bouguer gravity anomalies is higher than surrounding area. Throughout the crust, faults are nearly parallel distributed, just like a broom, while at the bottom of lower crust, the gravity anomalies link together with high gravity anomalies produced by BaodingShijiazhuang fault. These faults form the TPTZ together. High Bouguer gravity anomalies exist in nearly all detailed images beneath Beijing area, which are induced by upwelling of upper mantle and asthenospheric heat flow materials. The occurrence of Sanhe earthquake $\left(M_{\mathrm{S}} 8.0\right)$ is correlated with upwelling of the high density materials. And it is similar to Tangshan earthquake.

\section{Conclusions}

Surface gravity data with $2 \mathrm{~km}$ sampling interval were used to get the fine crustal structure beneath Beijing and its surrounding regions. We apply wavelet multi-scale analysis method to separating gravitational potential field so as to invert crustal structure. Logarithm power spectrum method was used to calculate the approximate source depth. Bouguer gravity fields were separated successfully, with the shallow gravity anomalies separated from deep ones, and local gravity anomalies separated from regional ones. And then homogeneous features of density and seismogenic environments were analyzed in this paper.

Researches indicate Beijing is situated in the interaction area of Zhangjiakou-Bohai tectonic zone (ZBTZ) and Taihang piedmont tectonic zone (TPTZ). The 
crustal structure beneath Beijing is very complicated, especially in middle and upper crust. The crustal density is inhomogeneous in lateral direction. The upper and middle crusts are divided by different striking faults into many small-scale tectonic units like uplifts and depressions; all these units exhibit different gravity anomalies. With the depth increasing to the bottom of lower crust, small-scale units disappear gradually, and they are replaced by large-scale tectonic units. The North China basin (NCB) is interlaced with several NE-striking high and low gravity anomalies, which was produced by Jizhong depression, Cangxian uplift and Huanghua depression, etc. The Cenozoic era ZBTZ intersects with these NE-striking tectonic units, and small earthquakes occurred frequently on ZBTZ. High Bouguer gravity anomalies exist throughout the whole lithosphere of Beijing and Tangshan area. They are induced by upwelling of upper mantle and asthenospheric heat flow materials along TPTZ and ZBTZ. The occurrence of Sanhe and Tangshan earthquakes were inferred to be related to these uppermost mantle and asthenospheric materials. In west of Taihangshan, gravity anomalies are correlated with surface geological and topographic features in upper and middle crusts. Gravity anomalies and velocity anomalies are correlated with each other in upper crust. The earthquakes mainly occurred in upper and middle crusts, especially in transitional regions between high gravity anomalies and low gravity anomalies beneath Beijing and its surrounding regions. These high and low gravity anomalies correspond to uplifts and depressions. The structure in uppermost mantle is comparatively simple compared with the crust. Our results will improve recognization of crustal structure and seismogenic environment beneath Beijing and its surrounding regions.

Acknowledgements The research was supported by professional fund for basic scientific research of Chinese Central-level Public-welfare College/Institute from Chinese Finance Ministry, and Institute of Crustal Dynamics, China Earthquake Administration (ZDJ2007-1). We thank the editor and anonymous reviewers for providing constructive comments and suggestions which improved the manuscript.

\section{References}

Castagna J P, Batzle M L and Eastwood R L (1985). Relationships between compressional-wave and shearwave velocities in elastic silicate rocks. Geophysics $\mathbf{5 0}(4)$ : 4571-4 581.

Chen B (2004). Geophysical Features and Geological Inter- pretation of Cenozoic Sedimentary Basin Basement in the Northeast Area of South China Sea. Tongji University Press, Shanghai, 130pp (in Chinese).

Cianciare B and Marcar H (1976). Interpretation of gravity anomalies by means of local power spectra. Geophysical Prospecting 24: 273-286.

Diao B, Wang J L and Cheng S Y (2007). The confirmation of decomposition level in wavelet multi-resolution analysis for gravity anomalies. Earth Science-Journal of China University of Geosciences 32(4): 564-568 (in Chinese with English abstract).

Fang L H, Wu J P and Lü Z Y (2009). Rayleigh wave group velocity tomography from ambient seismic noise in North China. Chinese J Geophys 52(3): 663-671 (in Chinese with English abstract).

Fang S M, Zhang X K, Jia S X, Duan Y H, Yang Z X and Qiu S Y (2002). Multi-scale decomposition of Bouguer gravity anomaly and seismic activity in north China. Journal of Geodesy and Geodynamics 22(1): 34-39 (in Chinese with English abstract).

Feng R, Zheng S Z and Huang G F (1989). Gravity field and structure of the sedimentary layer in North China. Chinese J Geophys 32(4): 385-398 (in Chinese with English abstract).

Gardner G H F, Gardner L W and Gregory A R (1974). Formation velocity and density - the diagnostic basics for stratigraphic traps. Geophysics 39(6): 770-780.

Han D H, Nur A and Morgan D (1986). Effects of porosity and clay content on wave velocities in sandstones. Geophysics 51(11): 2 093-2 107.

Han W G, Li H M and Yang Y L (1997). Analysis of rock elastic parameters of Jiyang depression and its measure in lab. Geophysical Prospecting for Petroleum 36(1): 21-27 (in Chinese with English abstract).

Hou Z Z and Yang W C (1997). Wavelet transform and multi-scale analysis on gravity anomalies of China. Chinese J Geophys 40(1): 85-95 (in Chinese with English abstract).

Huang J L and Zhao D P (2004). Crustal heterogeneity and seismotectonics of the region around Beijing, China. Tectonophysics 385: 159-180.

Huang J L and Zhao D P (2005). Three dimensional P wave velocity tomography and deep structure related to strong earthquake in Capital area. Chinese J Geophys 50(4): 348-355 (in Chinese with English abstract).

Huang J L and Zhao D P (2009). Seismic imaging of the crust and upper mantle under Beijing and surrounding regions. Phys Earth Planet Inter 173: 330-348.

Jia S X and Zhang C K (2005). Crustal structure and comparison of different tectonic blocks in North China. Chinese J Geophys 48(3): 611-620 (in Chinese with English abstract).

Jia S X, Zhang C K, Zhao J R, Fang S M, Liu Z and Zhao J M (2009). Crustal structure of the rift-depression basin 
and Yanshan uplift in the northeast part of North China. Chinese J Geophys 52(1): 99-110 (in Chinese with English abstract).

Jiang W L, Zhang J F, Jiao M M and Lu J (2010). Research on structural characteristic in Capital area based on wavelet multi-scale method of Bouguer gravity anomaly. Acta Geologica Sinica 84(4): 457-465 (in Chinese with English abstract).

Jin A S, Liu F T and Sun Y Z (1980). Three-dimensional $\mathrm{P}$ velocity structure of the crust and upper mantle under Beijing region. Chinese J Geophys 23(2): 172-182 (in Chinese with English abstract).

Lei J S, Xie F R, Lan C X, Xing C Q and Ma S (2008). Seismic images under the Beijing region inferred from $\mathrm{P}$ and PmP data. Phys Earth Planet Inter 168: 134-146.

Li Q Z (1992). Principles of P- and S- waves of rock. Oil Geophysical Prospecting 27(2): 1-12.

Li A R, Cheng F Y, Gu C Z and Xu Y J (1984). Seismotectonic analysis of the gravity anomaly gradient in Eastern China. Seismology and Geology 6(2): 53-65 (in Chinese with English abstract).

Li Z W, Xu Y, Hao T Y, Liu J S and Zhang L (2006). Seismic tomography and velocity structure in the crust and upper mantle around Bohai Sea area. Chinese J Geophys 49(3): 797-804 (in Chinese with English abstract).

Liu F T, Li Q, Wu H, Hu G and Liu J H (1989). On the tomographic inverse method used in velocity image reconstruction. Chinese J Geophys 32(1): 46-61 (in Chinese with English abstract).

Liu G D (1987). The Cenozoic rift system of the North China plain and the deep internal process. Tectonophysics 133: $277-285$.

Liu G D (2002). The characteristics of geophysical fields on the China seas. Progress in Geophysics 17(1): 1-12 (in Chinese with English abstract).

Liu S M, Shen C Y, Sun S A and Chen B Y (2004). Analysis of characteristics of wavelet multi-scale decomposition. Journal of Geodesy and Geodynamics 24(2): 24-41 (in Chinese with English abstract).

Luo Y, Chong J J, Ni S D, Chen Q F and Chen R (2008). Moho depth and sedimentary thickness in Capital region. Chinese J Geophys 51(4): 1135-1145 (in Chinese with English abstract).

Lou H and Wang C Y (2005). Wavelet analysis and interpretation of gravity data in Sichuan-Yunnan region, China. Acta Seismologica Sinica 18(5): 552-561.

Ma L and Zheng S H (1998). Depth distribution of Moho discontinuity beneath the Beijing and its adjacent area. Earthquake Research in China 14(1): 1-13 (in Chinese with English abstract).

Ma Z G and Xie J G (2005). Relationship among compressional wave, shear wave velocities and density of rocks. Progress in Geophysics 20(4): 905-910 (in Chinese with English abstract).
Ma Z J, Gao X L and Song Z F (2006). Analysis and tectonic interpretation to the horizontal-gradient map calculated from Bouguer gravity data in the China mainland. Chinese J Geophys 49(1): 106-144 (in Chinese with English abstract).

Mallat S (1989). A theory for multi-resolution signal decomposition: the wavelet representation. IEEE Transactions on Pattern Analysis and Machine Intelligence 11: 674693.

Mallat S and Hwang W L (1992). Singularity detection and processing with wavelets. IEEE Transactions on Information Theory 38(2): 617-643, doi:10.1109118.119727.

Mavko G, Mukerji T and Dvorkin J (1998). The Rock Physics Handbook: Tools for Seismic Analysis in Porous Media. Cambridge University Press, Cambridge, 340pp.

Pei J X, Han B and Zhang X H (2007). Research on deep structures of East China Sea by combining upward continuation and wavelet analysis methods. Marine Geology and Quaternary Geology 27(6): 55-59 (in Chinese with English abstract).

Qi C, Zhao D P, Chen R, Chen Q F and Wang B S (2006). $\mathrm{P}$ and $\mathrm{S}$ wave velocity structure and its relationship to strong earthquakes in the Chinese capital region. Chinese $J$ Geophys 49(3): 805-815 (in Chinese with English abstract).

Smith G C and Gidlow P M (1987). Weighted stacking for rock property estimation and detection of gas. Geophysical Procspecting 25(9): 993-1 014 (in Chinese).

Sun R M and Liu F T (1995). Crust structure and strong earthquakes in Beijing, Tianjin and Tangshan area I. Pwave velocity structure. Chinese J Geophys 38(5): 599607 (in Chinese with English abstract).

Wang F Y, Zhang X K, Chen Q F, Chen R, Zhao J R, Yang Z X and Pan S Z (2005). Fine tomographic inversion of the upper crust $3-\mathrm{D}$ structure around Beijing. Chinese $J$ Geophys 48(2): 359-366 (in Chinese with English abstract).

Wang H (2005). Research of Wavelet Multi-Scale Analysis Applied on Earth Gravity Field. Wuhan University Press, Wuhan, 1-119 (in Chinese with English abstract).

Wang R B, Gu G H, Xu J and Zhou W (2004). Discussion on characteristics of crustal deformation along the Zhangjiakou-Penglai seismotectonic zone. Seismology and Geology 26(4): 586-596 (in Chinese with English abstract).

Wang W R, Li F, Yan J G and Ke B G (2009). Wavelet multi-scale analysis on gravity anomaly and inner structure of the Moon. Chinese J Geophys 52(7): 1693-1699 (in Chinese with English abstract).

Wu J, Gao Y, Chen Y T and Huang J L (2007). Seismic anisotropy in the crust in northwestern capital area of China. Chinese J Geophys 50(1): 209-220 (in Chinese with English abstract). 
Xu J, Niu L F, Wang C H and Han Z J (1996). Tangshan-Hejian-Cixian newly generated seismotectonic zone. Seismology and Geology 18(3): 193-198 (in Chinese with English abstract).

Xu X W, Ran R K, Zhou B G, Yin G M, Li J H and Liu W Z (1998). Seismotectonic environment and macroscope destroy features of Zhangbei-Shangyi earthquake. Seismology and Geology 20(2): 135-145 (in Chinese).

Yang B J, Liu W S, Wang X C, Li Q X, Wang J M, Zhao X P and Li R L (2005). Geophysical characteristics of Daxinganling gravitational gradient zone in the East China and its geodynamic mechanism. Chinese $J$ Geophys 48(1): 86-97 (in Chinese with English abstract).

Yang W C (1993). Applied Seismic Tomography. Geological Publishing House, Beijing, 230pp (in Chinese).

Yang W C, Shi Z Q, Hou Z Z and Cheng Z Y (2001). Discrete wavelet transform for multiple decomposition of gravity anomalies. Chinese J Geophys 44(4): 534-541 (in Chinese with English abstract).

Ye H, Shedlock K and Hellinger S (1985). The North China basin, an example of a Cenozoic rifted intraplate basin. Tectonics 4: 153-169.

Yin X H, Liu T Y and Liu Z P (1993). Isostatic anomalies of gravity and geologic structures of the surface and shallow crust. Seismology and Geology 15(2): 149-156 (in Chinese with English abstract).
Yin X H, Shi Z Q and Liu Z P (1980). Basic features of the regional gravity field in the China mainland. Seismology and Geology 2(4): 69-75 (in Chinese with English abstract).

Yu X W, Chen Y T and Wang P D (2003). Threedimensional $\mathrm{P}$-wave velocity structure in Beijing area. Acta Seismologica Sinica 16(1): 1-15.

Zeng H L (2005). Gravity Field and Gravity Prospecting. Geological Publishing House, Beijing, 273pp (in Chinese).

Zhang C Y and Qiu Q X (1998). Wavelet analysis and the prospects for its applications on gravity. Progress in Geophysics 13(2): 73-85 (in Chinese with English abstract).

Zhang H Z, Fang J and Zhang Z Z (2006). Application of wavelet analysis in the interface inversion of gravity field. Geomatics and Information Science of Wuhan University 31(3): 233-236 (in Chinese with English abstract).

Zhang J S and Wang H Y (2005). Gravity and magnetic characteristics and tectonic divisions of the Yanshan area. Acta Geoscientic Sinica 26(4): 349-354 (in Chinese with English abstract).

Zhang W C, Yang D X, Chen Y J, Qian Z, Zhang C W and Liu H F (2008). Sedimentary structural characteristics and hydrocarbon distributed rules of Jizhong depression. Acta Geologica Sinica 82(8): 1103-1112 (in Chinese with English abstract). 